\title{
CFD Simulation and Optimization of Very Low Head Axial Flow Turbine Runner
}

\author{
Yohannis Mitiku Tobo ${ }^{a,}$, A. Venkata Ramayya ${ }^{b}$, and Getachew Shunki Tibbac \\ a,b,c Jimma University, Jimma Institute of Technology, School of Mechanical Engineering, Jimma, Ethiopia
}

\begin{abstract}
The main objective of this work is Computational Fluid Dynamics (CFD) modelling, simulation and optimization of very low head axial flow turbine runner to be used to drive a centrifugal pump of turbine-driven pump. The ultimate goal of the optimization is to produce a power of $1 \mathrm{~kW}$ at head less than $1 \mathrm{~m}$ from flowing river to drive centrifugal pump using mechanical coupling (speed multiplier gear) directly. Flow rate, blade numbers, turbine rotational speed, inlet angle are parameters used in CFD modeling, simulation and design optimization of the turbine runner. The computed results show that power developed by a turbine runner increases with increasing flow rate. Pressure inside the turbine runner increases with flow rate but, runner efficiency increases for some flow rate and almost constant thereafter. Efficiency and power developed by a runner drops quickly if turbine speed increases due to higher pressure losses and conversion of pressure energy to kinetic energy inside the runner. Increasing blade number increases power developed but, efficiency does not increase always. Efficiency increases for some blade number and drops down due to the fact that change in direction of the relative flow vector at the runner exit, which decreases the net rotational momentum and increases the axial flow velocity.
\end{abstract}

Keywords: Computation, Efficiency, Irrigation, Modelling, Optimization, Power, Turbine driven pump

Article History: Received May 26, 2015; Received in revised form July 19, 2015; Accepted September 20, 2015; Available online How to Cite This Article: Tobo, Y.M., Ramayya, A.V., and Tibba, G.S. (2015) CFD Simulation and Optimization of Very Low Head Axial Flow Turbine Runner, 4(3), 181-188.

http://dx.doi.org/10.14710/ijred.4.3.181-188

\section{Introduction}

Energy security is the driving force for sustainable economic and social development of developed and developing counties (Kulkarni \& Anil, 2014; Mondal \& Mandal, 2013; Adejumobi, Adebisi, \& Oyejide, 2013; Tilahun, 2011). Renewable energy is the supporting pillar of environment, economic and social development and generates additional employment, which leads to social improvement of the nation (Mondal \& Mandal, 2013; Vineesh \& Selvakumar, 2012; Baburaj et al., 2013).

Agriculture is the core driver for Ethiopia's growth and long-term food security. The stakes are high: 15 to $17 \%$ of government of Ethiopia's expenditures is committed to the sector; agriculture directly supports $85 \%$ of the population's livelihoods (MoFED, 2010; Awuchalew, 2010) 43\% of gross domestic product (GDP), and over $80 \%$ of export value (Awuchalew, 2010; Tilahun et al., 2014; Hagos et al., 2010). Agriculture is the mainstay of the Ethiopian economy in terms of income, employment and generation of export revenue (Hagos, Makombe, Namara, \& Awuchale , 2010).

Agriculture in Ethiopia is dominated by smallholder rain-fed systems but, low and erratic rainfall limits productivity and food security. Consequently, investment in small-scale irrigation has been identified as a key poverty reduction strategy (Hagos et al., 2010). Recent estimates indicate that the total irrigated area under small-scale irrigation in Ethiopia has reached about 853,000 hectares during the last implementation period of Plan for Accelerated and Sustained Development to End Poverty (PASDEP) $2009 / 10$ and the plan set for development of small scale irrigation is $1,850,000$ hectares, which is planned to be achieved by the end of the five years growth and transformation plan (GTP) of 2015 (MoFED, 2010; Minstry of agriculture and natural resource, 2011).

Small hydropower technology is one of the best suited technologies for off-grid power supply but, it is

*Corresponding author: yohannis.mitiku@gmail.com 
Citation: Tobo, Y.M., Ramayya, A.V., and Tibba, G.S.. (2015), CFD Simulation and Design Optimization of Very Low Head Axial Flow Turbine Runner. Int. Journal of Renewable Energy Development, 4(3), 181-188, http://dx.doi.org/10.14710/ijred.4.3.181-188

$\mathrm{P}$ a g e $\mid 182$

extremely dependent on specific site (Ramos, Simao, \& Kenov, 2012, Vineesh \& Selvakumar, 2012). Small scale hydropower has a high potential in rural electrification and expansion of small scale irrigation using either electric motor pump or using the concept of turbine driven pump i.e. delivering mechanical energy of axial flow turbine directly to centrifugal pump using mechanical coupling (gear system to increase speed of pump).

Low heads, high discharges like propeller turbine, with little variability, easy to manufacture and with low costs associated with it to provide energy using urban water pipe. They are appropriate for operation under almost constant-flow conditions, as for water pipe systems equipped with a discharge control valve (Ramos, Simao, \& Borga, 2012). Micro hydro power left undeveloped is because of economic constraints, although the running cost for micro hydro scale are very low, the initial capital cost are high (Baburaj et al., 2013).

The use of an axial flow propeller turbine in remote area application was first demonstrated by Peter Garman in 1978. Turbines mounted on pontoons or suspended using pivot arms from river banks or from jetties are reported able to produce about $1 \mathrm{~kW}$ to $2 \mathrm{~kW}$ of electrical power suitable for remote homes. However several deployments have experienced major problems with debris attaching to the turbines, resulting in interrupted operation (Anyi \& Kirke, 2010).

Analyzing flow behavior inside turbine runner is very complex due to interaction of stationary and rotating blade rows. The conventional method to determine the turbine performance is model testing. Applying this method for different alternatives in design optimizations is extremely costly and time consuming. Computational fluid dynamics (CFD) has become a cost effective tool for predicting detailed flow information in turbine space to enable the selection of best design (Prasad, 2012; Prasad \& Khare, 2012). Using CFD simulation on computers, the response time is very short and the modification can be investigated in a short time (Busea \& Jianu, 2004).

CFD simulation provides detailed flow information inside turbine space effectively and performance characteristics of turbine in terms of global as well as local parameters (Chica et al., 2013 and Prasad, 2012). The application of CFD is steadily increasing to improve design of hydraulic turbines (Prasad, Sayann, \& Krishnamachar, 2009).

Prasad \& Khare, 2012; Ramos, Simao, \& Borga, 2012; Vu, Koller, \& Gauthier, 2010; Vu, Koller, \& Gauthier, 2010; did a 3-D modelling using ANSYS CFX together with a blade model configuration (BMC) of axial flow hydraulic turbine and validated their work with experiment. The computed result and test result has good agreement at design and off design conditions according to their report.

The development of computer-based tools with more efficient algorithms has allowed a substantial improvement in hydraulic turbine modeling, simulation and design optimization. GAMBIT and 3-D FLUENT is used to define the geometry and solve flow to analysis of fluid flow through blade. The application of the minimum pressure coefficient and free vortex criterions for axial-flow hydraulic turbines cascade geometry design were the main goal of the simulation and experimental test. The optimum value was concluded that design value of the minimum pressure coefficient lies within range of -2.25 to -1.27 have loading coefficient with the minimum losses in the shock free flow with maximum efficiency of $90 \%$ (Sutikno \& Adam, 2011).

Most irrigation schemes, which are professionals' design approach starting from site selection, are considerably less demand driven and they are costly for small scale irrigation systems. Small scale irrigation which has high potential in increasing income of farmers and ensures food security faces the following four major challenges: (1). Cost of civil work is too high to design, construct diversion and distribution lines, (2). Large part of the rural areas is not connected to on/off grid power supplies and can not to utilize electric motor pumps, (3). Cost of fuel is increasing from time to time and farmers are becoming unable to afford running costs of fueled engine pumps (4). Most of small scale water pumping technologies requires human power to operate and their operation is intermittent due to unavailability of operators. For example treadle pump, and rope pump require continuous and intensive human power to operate. To overcome these problems, renewable energy assisted small scale irrigation technologies are becoming more popular.

The innovative work of this paper is to pump water from a river, without external electrical or fuel sources, using energy just from flow of the river. This technology is a turbine-driven pump (TDP) or turbopump. In TDP axial flow turbine is coupled to a centrifugal pump with a gear with aim of increasing pump speed. The turbine is run by the flowing river.

This work focuses on CFD modelling and simulation of axial flow turbine which is one component of turbine driven pump. Design and optimization of a centrifugal pump has already been published in other journal (Mitiku, Ramayya \& Shunki, 2015).

\section{Materials and Methods}

The formulation of an optimization problem begins with identifying the underlying design variables, which are primarily varied during the optimization process. Design variables are constraints which are highly sensitive to the suitable working of the design.

Modeling and simulation of axial flow turbine runner was done using ANSYS 14.5 CFX package. Design optimization of axial flow turbine runner was done at a 
flow rate of 130,145, 160, 175 and $190 \mathrm{~L} / \mathrm{s}$, blade number is varied 3 to 10 with one step size and rotational speed of $325,350,375,425,475$ and 500rpm and runner inlet angles $\left(\beta_{1}\right), 14^{0}$ to $94^{0}$ with 10 step size.

\subsection{Governing Equations}

a. Continuity equation

$$
\frac{\partial u_{i}}{\partial x_{i}}+\frac{\partial v_{j}}{\partial y_{j}}=0
$$

b. Momentum equation: for the rotor rotating in a fixed frame of reference momentum equation is defined by

$$
\begin{aligned}
& \frac{\partial U_{i}}{\partial t}+U_{j} \frac{\partial U_{i}}{\partial x_{j}}+\frac{1}{\rho} \frac{\partial P}{\partial x_{j}}- \\
& \frac{\partial}{\partial x_{j}}\left[\left(v+v_{t}\right)\left(\frac{\partial U_{i}}{\partial x_{j}}+\frac{\partial U_{j}}{\partial x_{i}}\right)\right] \\
& =2 \varepsilon_{i j k} \Omega_{j} U_{k}+\Omega_{i} \Omega_{j} x_{j}-\Omega_{i} \Omega_{j} x_{i}
\end{aligned}
$$

The turbulent viscosity, considering $k-\varepsilon$ turbulence model, is obtained by

$$
v_{t}=c_{\mu} \frac{k^{2}}{\varepsilon}
$$

c. The turbulent kinetic energy ( $k$ ) and its dissipation rate $(\varepsilon)$ : are calculated using transport equations (4) and (5) respectively (Ruprecht, Bauer, Gentner, \& Lein, 1999).

$$
\begin{aligned}
& \frac{\partial k}{\partial t}+U_{j} \frac{\partial k}{\partial x_{j}}-\frac{\partial}{\partial x_{j}}\left[\left(v+\frac{v_{t}}{\sigma_{k}}\right) \frac{\partial \varepsilon}{\partial x_{j}}\right] \\
& =G-\varepsilon \\
& \frac{\partial \varepsilon}{\partial t}+U_{j} \frac{\partial \varepsilon}{\partial x_{j}}-\frac{\partial}{\partial x_{j}}\left[\left(v+\frac{v_{t}}{\sigma_{\varepsilon}}\right) \frac{\partial \varepsilon}{\partial x_{j}}\right] \\
& =c_{1} \frac{\varepsilon}{k} G-c_{2} \frac{\varepsilon^{2}}{k}
\end{aligned}
$$

Where $\mathrm{G}$ is given by

$$
G=v_{t}\left(\frac{\partial U_{i}}{\partial x_{j}}+\frac{\partial U_{j}}{\partial x_{i}}\right) \frac{\partial U_{i}}{\partial x_{j}}
$$

The model equation constants values are: $c_{\mu}=0.09, \quad \sigma_{k}=1.0, \quad \sigma_{\varepsilon}=1.3, \quad c_{1}=1.44$ and $c_{2}=1.92$

\section{d. Turbine performance parameters}

The numerical result from the simulation gives pressure, velocity distribution and the non diemensional flow parameters. Head and hydraoulic efficiency of turbine are calculated from change in presure from turbine inlet to outlet. Equation 7 to 9 shows head available, head utlised by turbine and hydraulic efficiency of turbine.

Total head $\left(\mathrm{H}_{\mathrm{T}}\right)$

$H_{T}=\frac{T P_{i}-T P_{e}}{\rho g}$

Head utlized by runner $\left(\mathrm{H}_{\mathrm{R}}\right)$

$H_{R}=\frac{T P_{i}-T P_{e}}{\rho g}-H_{F R}$

Hydraulic efficiency $\left(\eta_{H}\right)$

$\eta_{H}=\frac{H_{R}}{H_{T}} * 100 \%$

\subsection{Axial Flow Turbine Modellng}

Geometry of axial flow turbine is created using ANSYS BladeGen. Blade width, hub and tip radius are defined first in blade geometry creation process, BladeGen. After defining blade dimensions 3-D geometry is generated next. Axial flow turbine is modelled and simulated for the following dimensions: hub diameter $151 \mathrm{~mm}$, tip /outside diameter $330 \mathrm{~mm}$, blade width $62 \mathrm{~mm}$ and blade number six.

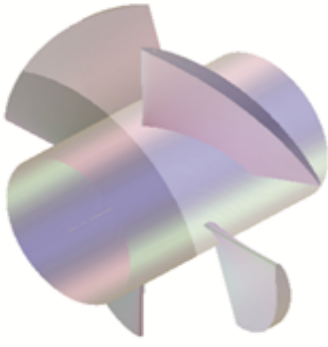

(a)

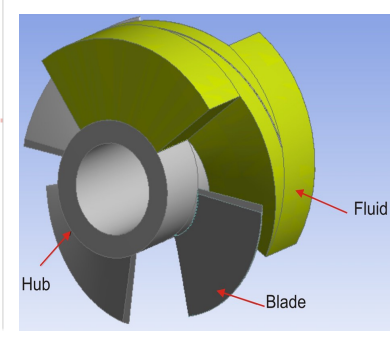

(b)
Fig 1. Turbine runner: (a) Solid domain and (b) Fluid and solid domain

All necessary components like blade number, blade angle, blade thickness, segment type, and other component of axial flow turbine are defined after geometry is created in ANSYS BladeGen.

\subsection{Meshing and boundary condition specification}

Meshing of axial flow turbine runner was done using ANSYS 14.5 CFX package. Boundary condition of the turbine was also defined at meshing stage. The table 1 shows the summary of the mesh statistics. 
Citation: Tobo, Y.M., Ramayya, A.V., and Tibba, G.S.. (2015), CFD Simulation and Design Optimization of Very Low Head Axial Flow Turbine Runner. Int. Journal of Renewable Energy Development, 4(3), 181-188, http://dx.doi.org/10.14710/ijred.4.3.181-188

$\mathrm{P}$ a g e $\mid 184$

Table 1 Mesh statistics

\begin{tabular}{ll}
\hline Total number of node & 233379 \\
\hline Total number of elements & 1316250 \\
\hline Total Number of Tetrahedrons & 1316250 \\
\hline Total number of faces & 50226 \\
\hline
\end{tabular}

Table 2 Boundary condition and initial values

\begin{tabular}{lll}
\hline $\begin{array}{l}\text { Boundary } \\
\text { name }\end{array}$ & $\begin{array}{l}\text { Type of boundary } \\
\text { condition }\end{array}$ & $\begin{array}{l}\text { Initial value of boundary } \\
\text { condition }\end{array}$ \\
\hline Inlet & Mass flow rate & $26.67 \mathrm{~L} / \mathrm{s} /$ passage \\
\hline Outlet & Opening/pressure & $0 \mathrm{~Pa}$ \\
\hline Periodic 1 & Interface & Rotational periodicity \\
\hline Periodic 2 & Interface & Rotational periodicity \\
\hline Shroud & Wall (rotating frame) & \\
\hline Hub & Wall (rotating frame) & \\
\hline
\end{tabular}

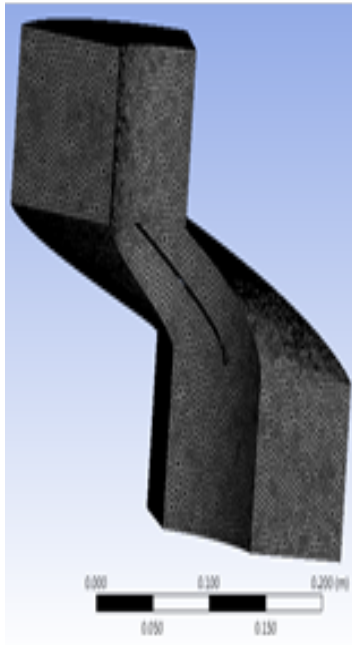

(a)

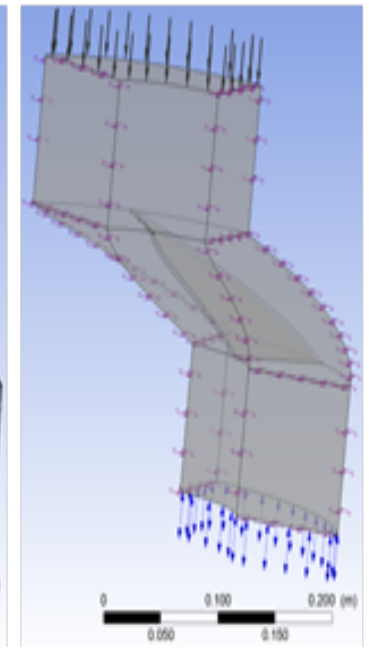

(b)
Fig. 2 (a) Axial flow turbine mesh (b) boundary conditions specification and b) Single blade in ANSYS CFX pre

\subsection{ANSYS CFX Simulation Flow Chart}

CFX pre is the stage where values of boundary condition and solver control (residual target and number of iteration) are defined.

Flow analyses were set to steady state, rotational periodicity and $\mathrm{Z}$ axis ration. The convergence residual target is set to $10^{-6}$. The solution is tested for grid independence solution.

\section{Result and Discussion}

The computed result of all design variables were analyzed and discussed in detail to identify the optimum performance of axial flow turbine. The computed result obtained at different design variables; effects of one design variable on other variables were assessed. Effects of flow rate, turbine speed, blade number, inlet angle were discussed in detail. The CFD computed results discussed below are compared with computational and experimental test results of available literature. The result shows that there is very good agreement of the computed results and available literatures.

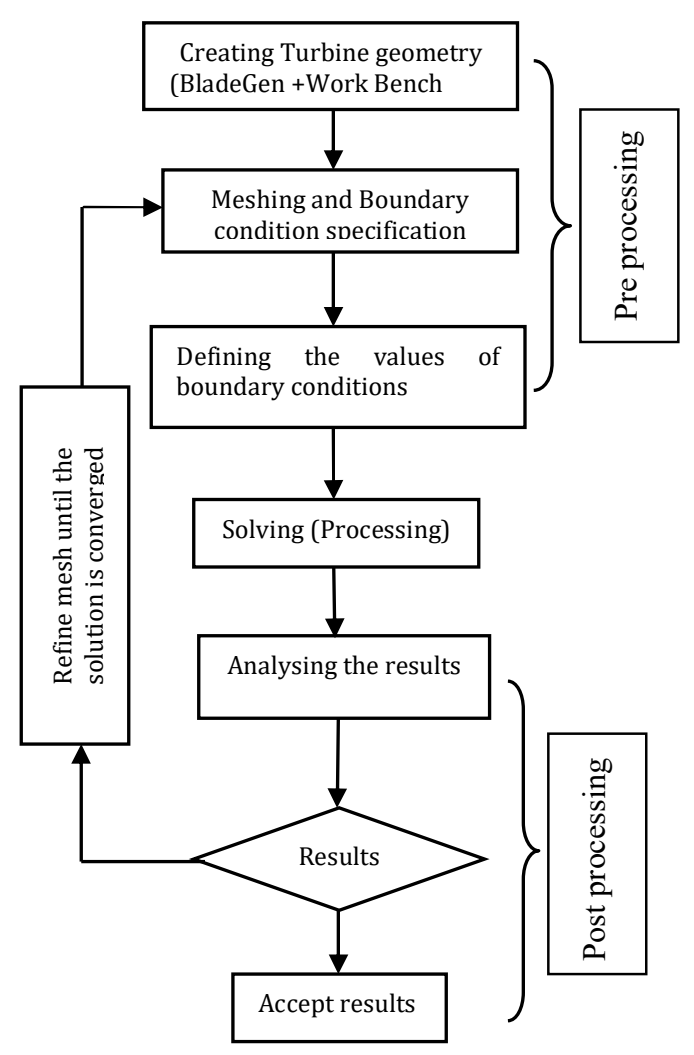

Fig. 3 ANSYS CFX solution flow chart

\subsection{Axial flow turbine performance at different flow rate}

For constant dimensions axial flow turbine performance were evaluated at different flow rate while keeping all other design variables constant. Efficiency of axial flow turbine increases rapidly until it reaches $74.92 \%$ which is at flow rate of $160 \mathrm{~L} / \mathrm{s}$ and then increases slowly till it finally becomes almost constant as shown in Fig. 4. This is due to change in total pressure loss from inlet to outlet in turbine runner is almost constant as flow rate increases which close agreement with (Beyon et al. 2013). 


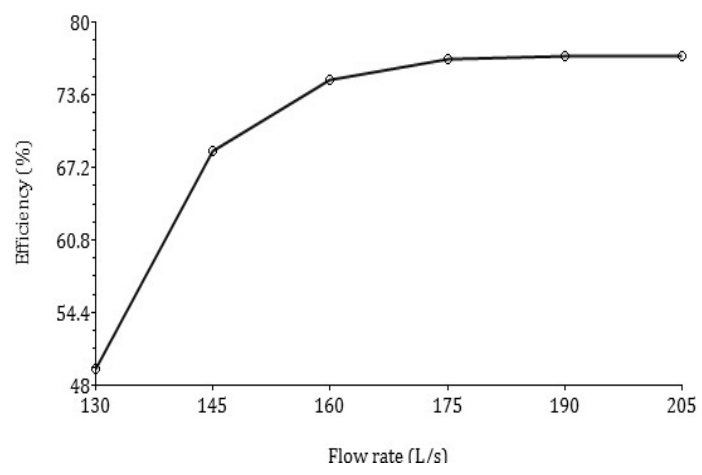

Fig. 4 Variation of efficiency with flow rate

\subsection{Axial flow turbine performance at different rotational speed}

All other design variables were kept constant while turbine speed varied. Fig. 5 and 6 shows that both power and efficiency decrease with increasing turbine speed because of higher pressure loss at high rotational speed in turbine runner as pressure energy is converted to kinetic energy. The computed result has good agreement with available literatures (Beyon, et al. 2013) and (Sutikno \& Adam, 2011).

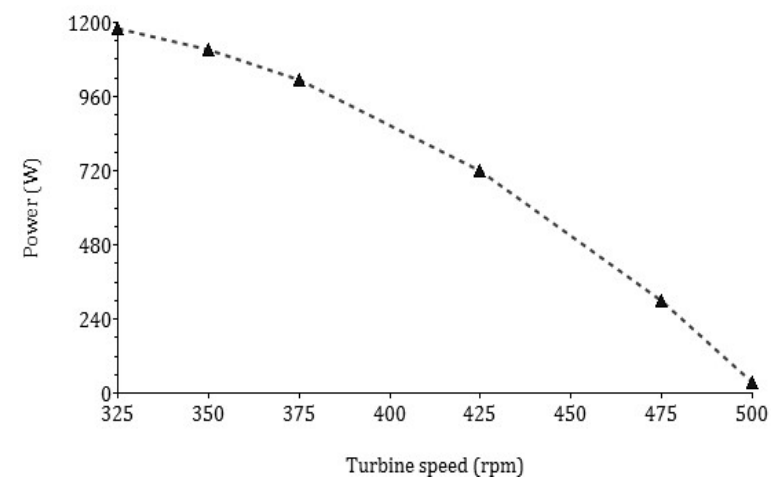

Fig. 5 Dependence of efficiency on turbine rotational speed

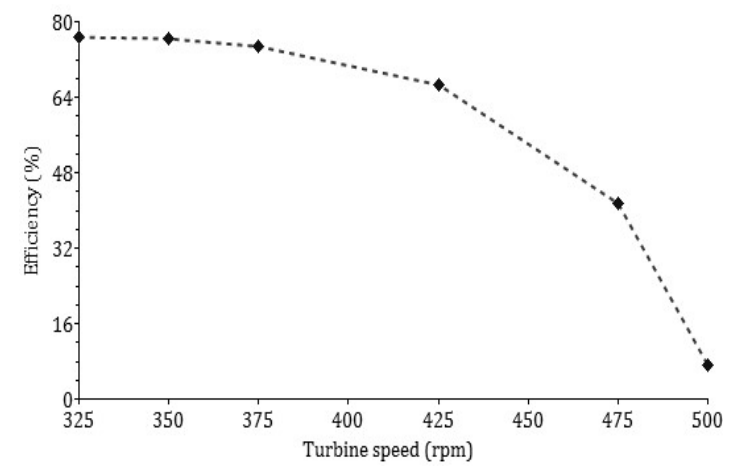

Fig. 6 Effect of turbine rotational speed on power delivered by turbine
3.1. Axial flow turbine performance at blade number and inlet angles

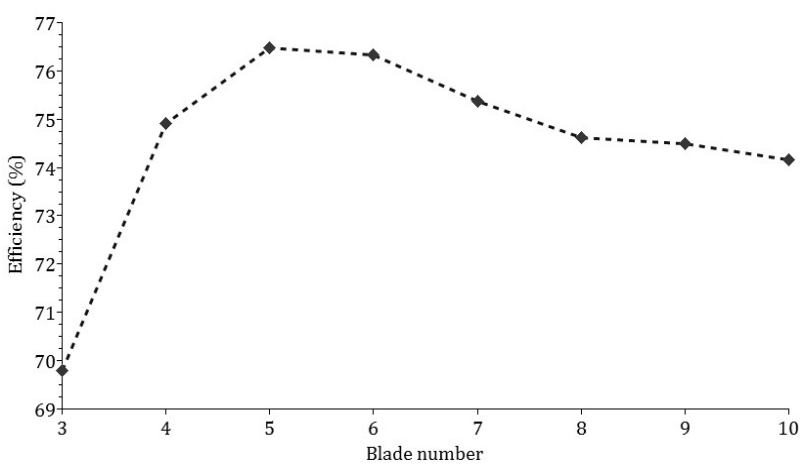

Fig. 7 Dependence of efficiency on blade number

Increasing blade number increases turbine efficiency for some blade number but, further increasing blade number decreases the net rotational momentum and increases the axial flow velocity. As observed from Fig. 7 the computed CFD result shows that the influence of blade number is more dominating factor compared to that of the blade height. Choice of blade number should be carefully made to enhance turbine efficiency. Turbine efficiency increases with increasing inlet angle see Fig. 8.

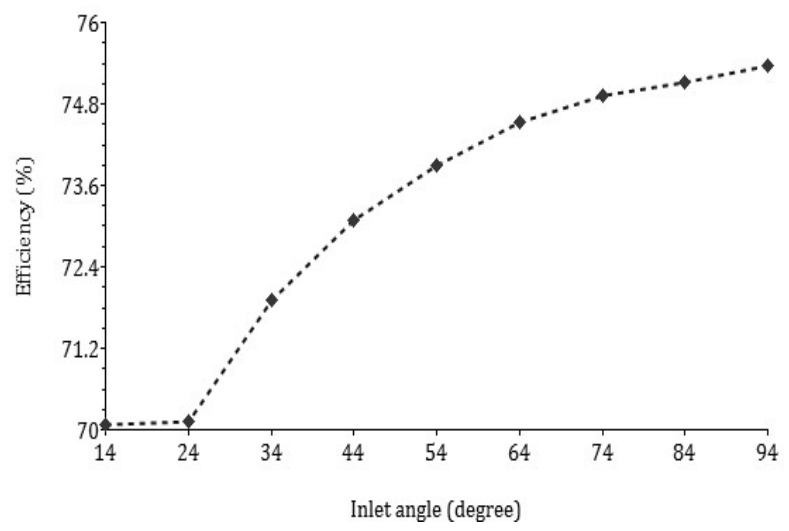

Fig. 8 Efficiency variation with increasing inlet angle

\subsection{Performance comparison at different flow rate and blade number}

Figure $9 \& 10$ show comparison of turbine efficiency with flow rate and speed for blade number 4 and 5 respectively. The efficiency of the runner decreases drastically with increase in blade number which is similar to Fig. 7. Figure 10 indicates that of higher pressure loss occurs as turbine rotational speed increases. Head utilized by turbine runner decreases as turbine speed increases hence, hydraulic efficiency turbine runner decreases as seen from Eq. (8) \& (9). From both figures (Fig. 9 \& 10) maximum efficiency is obtained for blade number 5 . 
Citation: Tobo, Y.M., Ramayya, A.V., and Tibba, G.S.. (2015), CFD Simulation and Design Optimization of Very Low Head Axial Flow Turbine Runner. Int. Journal of Renewable Energy Development, 4(3), 181-188, http://dx.doi.org/10.14710/ijred.4.3.181-188

$\mathrm{P}$ a g e $\mid 186$

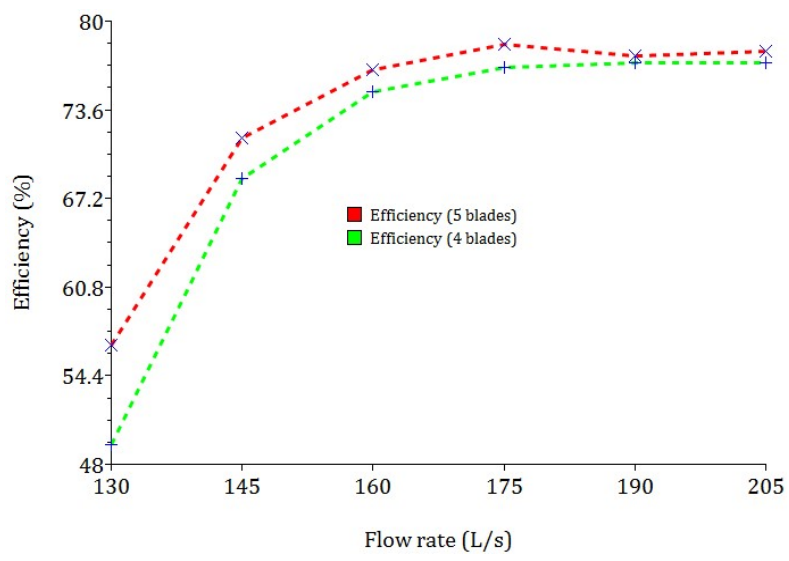

Fig. 9 Efficiency at different blade number and flow rate

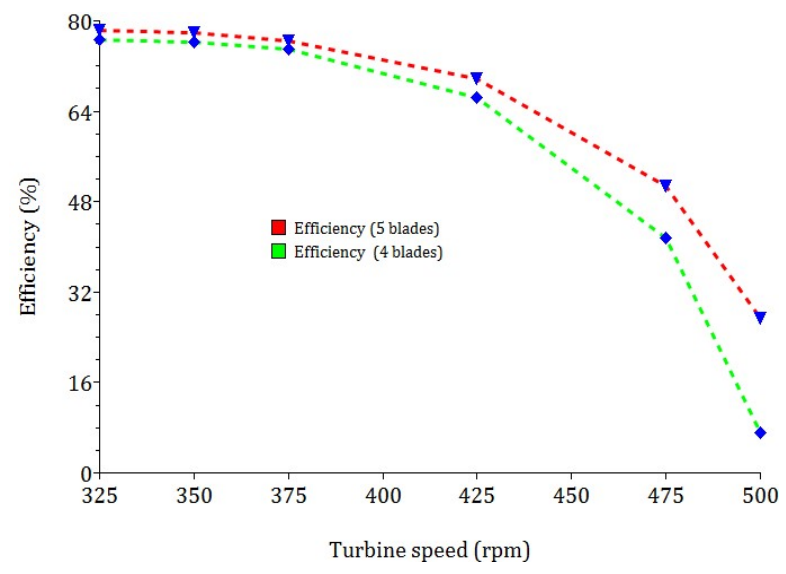

Fig.10 Efficiency at different blade number and speed

\subsection{Flow analysis inside axial flow turbine runner}

a) Flow analysis from hub to shroud

Fig. 11 and 12 shows the variation velocity component from hub to tip along the stream wise direction. The velocity component in $\mathrm{x}, \mathrm{y}$ direction and circumferential increases slowly along the streamline of blade, velocity component in Z-direction is almost decreasing along the stream wise as observed from Fig. 12. All velocity components start decreasing at the tip of the turbine runner.

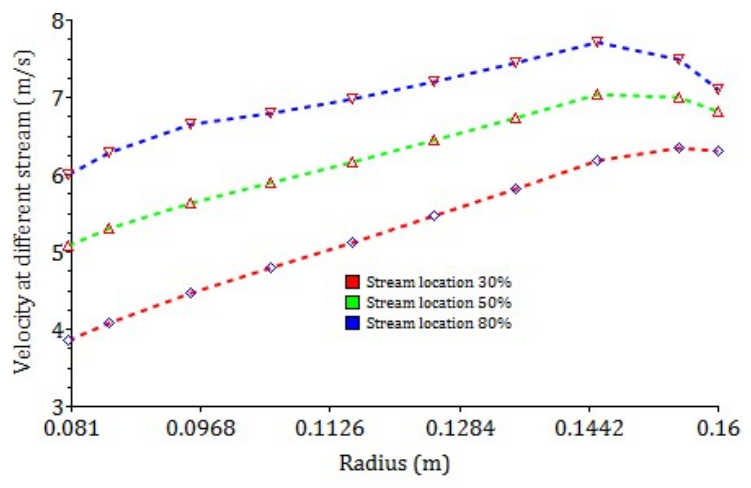

Fig. 11 Speed variation with turbine runner form hub to shroud

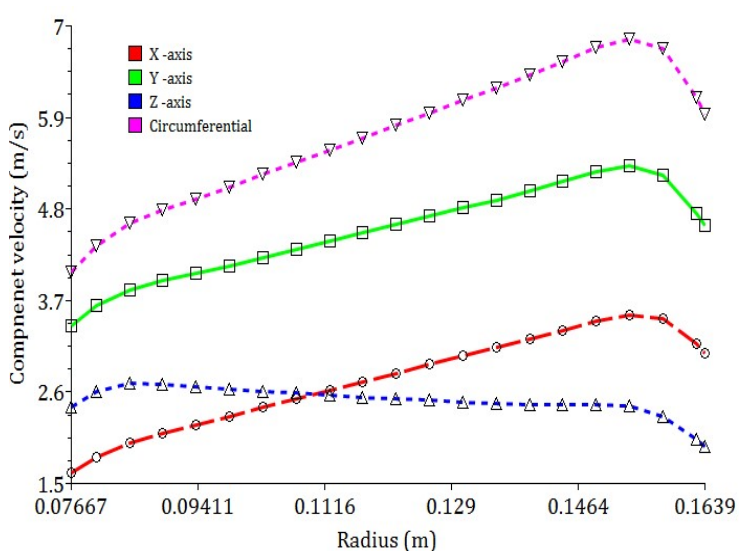

Fig. 12 Velocity component variation from hub to shroud

\section{b) Flow analysis from inlet to outlet}

Fig. 13 depicts that pressure drops gradually form the inlet to outlet stream line due to conversion of pressure energy of water to mechanical energy by the turbine runner. Turbine velocity increases from inlet to outlet as pressure energy of water is converted velocity (kinetic) energy due to turbine rotation.

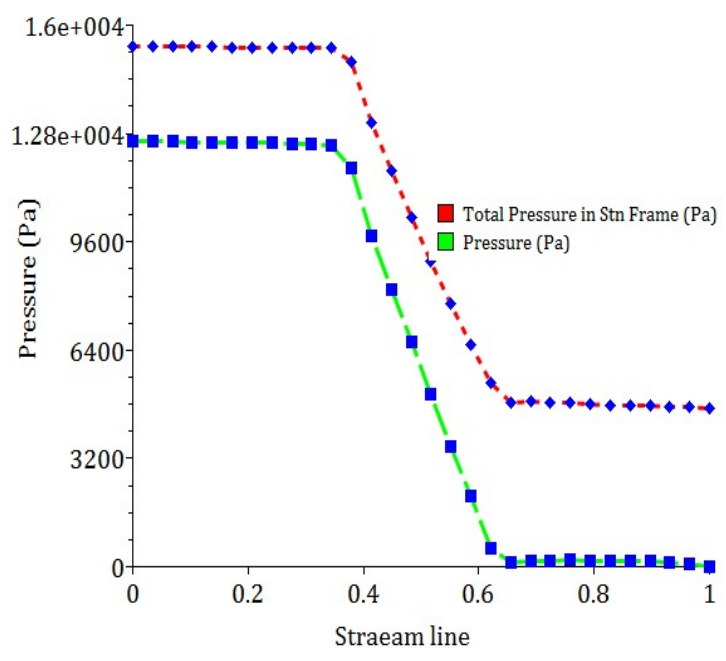

Fig. 13 Pressure variation along the stream line

\section{c) Blade to blade contour}

Pressure inside turbine decreases from Leading Edge (LE) to Trailing Edge (TE) as pressure energy is converted to mechanical energy inside turbine runner fig. 14 (a) \& (b). High pressure is exerted on the suction side of the turbine. Turbine velocity and relative velocity increases from LE to TE due to rotation of the runner as show on fig. 15 (a) \& (b). Stream line velocity increment at TE is shown on Fig. 16. 


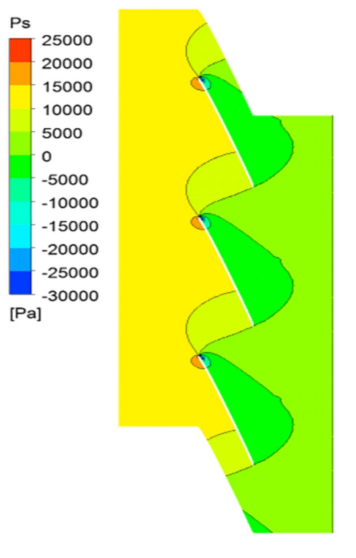

a)

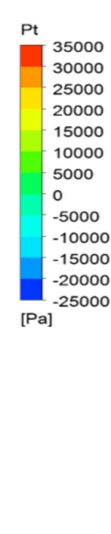

b)

Fig. 14 Contour of blade to blade a) static pressure b) total pressure

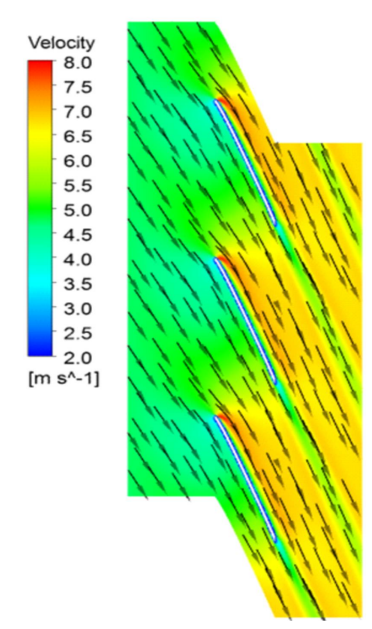

a)

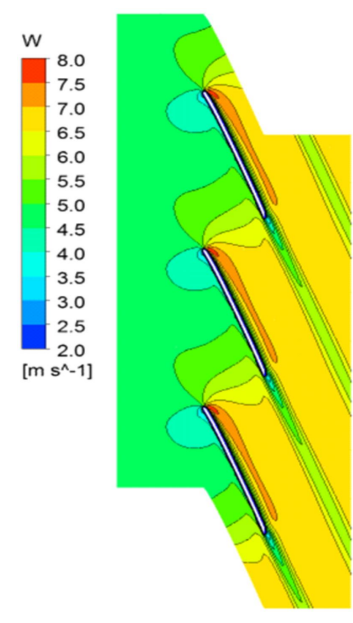

b)

Fig. 15 Blade to blade a) Velocity vector b) Relative velocity contour

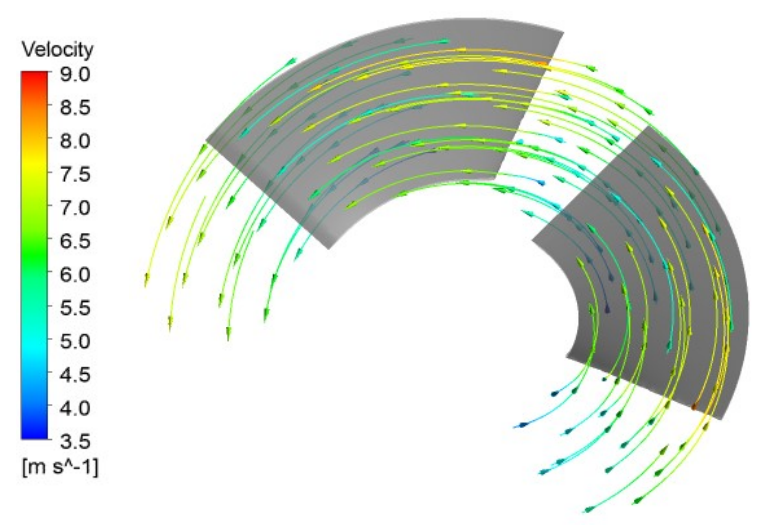

Fig. 16 Velocity Streamlines at Blade TE

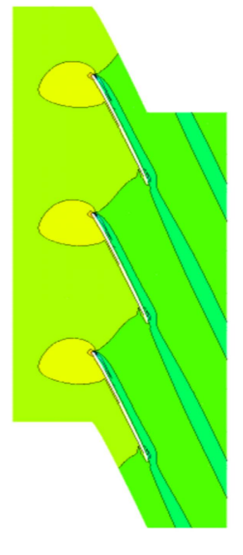

) 


$\begin{array}{ll}T P_{i} & \text { Total pressure at inlet } \\ T P_{e} & \text { Total pressure at exit } \\ x_{i} & \text { Cartesian coordinates } \\ \Omega_{i} & \text { Rotation vector } \\ \varepsilon & \text { Turbulence dissipation rate } \\ \varepsilon_{i j k} & \text { Cross-product tensor } \\ v_{t} & \text { Kinematic viscosity } \\ \rho & \text { Density } \\ \sigma_{k}, \sigma_{\varepsilon} & \text { Prandtl/Smith number for k- and } \varepsilon \text { - equations }\end{array}$

\section{Acknowledgement}

This paper would not come exist without financial, technical and moral support from others. The support from Jimma University and former Ethiopian Ministry of Water, Irrigation and Energy (MoWIE) are above all. We would like to acknowledge Jimma University and Ministry of Water, Irrigation and Energy (MoWIE) of Ethiopia for funding and supporting this paper.

\section{References}

Adejumobi, I. A., Adebisi, O. I., \& Oyejide, S. A. (2013). Developement of Small Hydro Power Potentials for Rural Electrifications. IJRRAS, $7(1), 105-110$.

Anyi, M., \& Kirke, B. (2010). Evaluation of small axial flow hydrokinetic turbines for remote community. Elsevier, Energy for Sustainable Development, 14, 110-116.

Awuchalew, S. B. (2010). Irrigation potential in Ethiopia constraints and opportunities for enhancing the system. International Water Management Institute (IWMI).

Baburaj, E., Sivaprakasam, R., Manikandan, C., \& Sudha, K. (2013). CFD Analysis of Pump as Turbine for Micro-Hydro Schemes. International Journal of Innovative Research in Science, Engineering and Technology, 2(3), 590-594.

Byeon, S.S, Boo, J.H., Park, J.Y., Kim, S. and Kim Y.J. (2013). Numerical study on the ow characteristics of low head small hydraulic turbine. Advanced Materials Research, 732-733, 436-442

Chica Arrieta, E. L., Florez, S. A., \& Sierra, N. I. (2013). Application of CFD to the design of the runner of a propeller turbine for small hydroelectric power plants. Rev. Fac. Ing. Univ. Antioquia, 181192.

Hagos, F., Makombe, G., Namara, R. E., \& Awuchalew , S. B. (2010). Importance of irrigated agriculture to the Ethiopian economy: Capturing the direct net benefits of irrigation. Acra: International Water Management Institute (IWMI) Sub regional Office for the Nile Basin and East Africa.

Kulkarni, S. H., \& Anil, T. R. (2014). Rural Electrification through Renewable Energy Sources. International Journal of Engineering Research (IJER), 3(6), 384-389.

Minstry of Agriculture and natural resource. (2011). Small-scale irrigation capacity building strategy for Ethiopia. Addis Ababa: The federal democratic republic of Ethiopia ministry of agriculture natural resource sector.

Mitiku. Y., Ramayya, V., \& Shunki, G. (2015), Turbine Driven Pump CFD Modelling and Simulation- a Centrifugal Pump Optimization forIrrigation, International Journal of Engineering and Technical Research (IJETR), 3(7), 154-159.

MoFED. (2010). Growth and Transformation Plan. Addis Ababa: Ministry of Finance and Economic
Mondal, M., \& Mandal, S. (2013). Remote Village Electrification through Renewable Solar energy:a Case Study of Sagar Island, West Bengal, India. The International Journal of Engineering And Science (IJES), 2(01), 201-205.

Prasad, V. (2012). Numerical simulation for flow characteristics of axial flow hydraulic. Energy Procedia, 14, 2060-2065.

Prasad, V., \& Khare, R. (2012). CFD: An effective tool for flow simulation in hydraulic reaction turbines. International Journal of Engineering Research and Applications (IJERA), 2(4), 1029 1035 .

Sutikno, P. \& Adam, K.I. (2011). Design, Simulation and Experimental of the Very Low Head Turbine with Minimum Pressure and FreeVortex Criterions. International Journal of Mechanical \& Mechatronics Engineering IJMME-IJENS, 11 (01), 9-16.

Ramos, H. M., Simao, M., \& Borga, A. (2012). CFD and experimental study in the optimization of an energy converter for low heads. CSCanada, Energy Science and Technology, 4(2), 1029 - 1035.

Ramos, H. M., Simao, M., \& Kenov, K. N. (2012). Low-Head Energy Conversion: A Conceptual Design and Laboratory Investigation of a Microtubular Hydro Propeller. ISRN Mechanical Engineering , 1-10.

Ruprecht, A., Bauer, C., Gentner, C., \& Lein, G. (1999). Parallel computation of stator-rotor interaction in an axial turbine. In ASME PVP Conference (pp. -). Boston: CFD Symposium.

Tilahun, A. (2011). Assessment of micro hydro power potential of selected Ethiopian rivers.- A case study in the northwest part of the country. Addis Ababa: Addis Ababa Institute of Technology, School of Graduate Studies, Addis Ababa University.

Tilahun, H., Erkossa, T., Michael, M., Hagos, F., \& Awuchalew, S. (2014). Comparative performance of irrigated and rainfed agriculture in Ethiopia. World Applied Sciences Journal, 14, 235-244.

Vineesh, V., \& Selvakumar, A. I. (2012). Design of Micro Hydel Power Plant. International Journal of Engineering and Advanced Technology (IJEAT), 2(2), 136-140.

Vu, T. C., Koller, M., \& Gauthier, M. D. (2010). Flow simulation and efficiency hill chart prediction for a propeller turbine. 25th IAHR Symposium Hydraulic Machinery and sytems, Timisora, Engineering Conferences Online (ECO) 